\title{
Environmental Enrichment Reduces Cocaine Seeking and Reinstatement Induced by Cues and Stress but Not by
} Cocaine

\author{
Claudia Chauvet', Virginie Lardeux', Steven R Goldberg', Mohamed Jaber' and Marcello Solinas*,' \\ 'Institut de Physiologie et Biologie Cellulaires, Université de Poitiers, CNRS, Poitiers, France; ${ }^{2}$ Preclinical Pharmacology Section, Behavioral \\ Neuroscience Research Branch, Intramural Research Program, NIDA, NIH, DHHS, Baltimore, MD, USA
}

\begin{abstract}
Whereas earlier studies have focused on the preventive effects of enriched environments (EE) in drug addiction, in a recent study we suggested that EE can also have 'curative' effects. In fact, we found that cocaine addiction-related behaviors can be eliminated by housing cocaine-treated mice in EE during periods of forced abstinence. However, those results were obtained with two simple models of addiction, conditioned place preference (CPP), and behavioral sensitization. In this study, we used intravenous drug self-administration procedures in rats to further investigate the beneficial effects of EE on cocaine addiction in a reinstatement model of relapse. Singly housed rats learned to self-administer cocaine during 10 consecutive daily sessions $(0.6 \mathrm{mg} /$ injection, $6 \mathrm{~h} /$ day). They were then housed three per cage in either standard environments (SE) or EE and were kept abstinent in the animal facility until testing for extinction and reinstatement. We found that 30 days of EE significantly and consistently reduced cocaine seeking during a 6-h extinction session. In addition, EE significantly reduced cue- and stress-induced reinstatement. Surprisingly, given our earlier results in mice with CPP, EE did not reduce cocaine-induced reinstatement regardless of the level of exposure to cocaine and the duration of the period of abstinence and exposure to EE. Altogether, these results support the hypothesis that EE can reduce cocaine-induced craving and highlight the importance of positive life conditions in facilitating abstinence and preventing relapse to cocaine addiction.

Neuropsychopharmacology (2009) 34, 2767-2778; doi: I0.1038/npp.2009.127; published online 9 September 2009
\end{abstract}

Keywords: environment; addiction; stress; relapse; protracted abstinence; behavioral therapy

\section{INTRODUCTION}

Cocaine addiction is a chronic brain disorder characterized by compulsive drug use that escapes control, by difficulties in remaining abstinent, and by a high risk of relapse. The mechanisms of relapse, and the factors that modulate it, can be studied in animals with reinstatement models (de Wit and Stewart, 1981; Epstein et al, 2006; Shalev et al, 2002). Environmental conditions have an important function in addiction, with negative environmental conditions increasing (Goeders, 2003; Marinelli and Piazza, 2002; Sinha, 2001) and positive environmental conditions decreasing the risks of addiction (Bardo et al, 2001; El Rawas et al, 2009; Jessor and Jessor, 1980; Solinas et al, 2009). Whereas all earlier studies have focused on the preventive effects of exposure to enriched environments (EE) on drug addiction, in a recent study we showed that EE can also have 'curative' effects and eliminate preexisting addiction-related behaviors (Solinas et al, 2008). In fact, exposing mice to a positive EE during a

*Correspondence: Dr M Solinas, Institut de Physiologie et Biologie Cellulaires, CNRS 6187, Pôle Biologie-Santé, Université de Poitiers, 40 avenue du Recteur Pineau, 86022 Poitiers Cedex, France,

Tel: + 33549 366343, Fax: + 33549 454014,

E-mail: marcello.solinas@univ-poitiers.fr

Received 3 April 2009; revised 24 July 2009; accepted 25 July 2009 30-day period of abstinence can reduce cocaine behavioral sensitization, drug seeking, and cocaine-induced reinstatement in conditioned place preference (CPP) procedures in mice (Solinas et al, 2008). In addition, the effects of $\mathrm{EE}$ on cocaine-induced reinstatement are paralleled by reductions in cocaine-induced activation of the brain circuitry involved in relapse (Solinas et al, 2008). Although these findings provide new evidence for the positive effects of $\mathrm{EE}$ on cocaine addiction, the models that were used mimic only some of the features of drug addiction in humans, namely the Pavlovian learning mechanisms involved in drug addiction (Bardo and Bevins 2000; Sanchis-Segura and Spanagel, 2006). On the other hand, drug self-administration procedures and reinstatement of extinguished drugseeking procedures have a higher level of validity (Epstein et al, 2006; Shalev et al, 2002) because with these procedures it is possible to appropriately mimic more complex aspects of human addiction, including voluntary drug taking and seeking behaviors, in experimental animals (Panlilio and Goldberg, 2007). In reinstatement of self-administration procedures, animals first learn to respond for drug injections and, then, this responding is extinguished by withdrawal of the drug reinforcer. Drug-seeking behavior can then be reinstated by drug priming injections, discrete drug-associated cues, or stressors (de Wit and Stewart, 
1981; Epstein et al, 2006; Shalev et al, 2002). Thus, drug selfadministration procedures allow for the study of each of these factors that can trigger relapse to drug use in humans (Epstein et al, 2006).

In this study, singly housed rats first learned to intravenously self-administer cocaine $(0.6 \mathrm{mg} /$ injection) during $6 \mathrm{~h}$ daily sessions for 10 days and were then housed three per cage in standard environments (SE) or EE (Laviola et al, 2008; Nithianantharajah and Hannan, 2006; van Praag et al, 2000). Rats were housed for a 30-day abstinence period in these environmental conditions and then underwent one 6-h extinction session followed by one or two 1-h reinstatement sessions according to a 'between-within' design (Shalev et al, 2002; Lu et al, 2004b). In these protocols, rats are allowed to self-administer a drug for several sessions and, subsequently, extinction training and relapse tests are performed on the same day after different periods of withdrawal. Reinstatement was triggered by cocaine-associated conditioned cues, by priming injections of cocaine or by the pharmacological stressor yohimbine, a drug that causes anxiety-like symptoms in humans and animals (Bremner et al, 1996a; Bremner et al, 1996b). As cocaine-induced reinstatement was not reduced by $\mathrm{EE}$ under these conditions, in contrast to our earlier findings in mice with CPP procedures (Solinas et al, 2008), we conducted three additional experiments in which (1) the level of cocaine exposure was reduced $(10 \times 3 \mathrm{~h}$ daily sessions), (2) the duration of exposure to EE was increased (90 days of abstinence in an EE), and (3) a 'between-day' reinstatement procedure was used (Shalev et al, 2002).

\section{MATERIALS AND METHODS}

\section{Subjects}

Adult (11-12 weeks of age) male Sprague-Dawley rats (Janvier, France) experimentally naive at the start of the study were housed in a temperature- and humiditycontrolled room and maintained on a 12-h light/dark cycle (light on at 7.00 AM). All experiments were conducted during the light phase in accordance to E.C. regulations for animal use in research (86/609/EEC).

\section{Housing Conditions}

On arrival, rats were housed three per cage for about 1 week before intrajugular catheterization surgery. After surgery, rats were housed individually during the entire period of active cocaine self-administration to limit catheter loss because of reciprocal chewing. At the end of the last cocaine self-administration session, rats were pseudo-randomly divided into two groups, one housed in SE and the other in EE conditions, with similar levels of cocaine selfadministration in the two groups. For SE, rats were housed in groups of three in cages sized $60 \times 38 \times 20 \mathrm{~cm}$. For EE, rats were housed in groups of three in cages sized $80 \times 50 \times 100 \mathrm{~cm}$. Each EE cage contained a house, a running wheel, three floors connected by ramps or tunnels and four toys that were changed once per week. For experiments 1,2, 3, and 4, rats were housed in the animal facility in SE or EE housing conditions during a 30-day period of abstinence. For experiment 5, rats were kept abstinent from drug for 90 days in SE or EE housing conditions (see Figure 1 for a schematic representation of the experimental procedures). For experiment 6 , rats were housed in SE or EE for eleven days during which they underwent extinction and reinstatement tests.

\section{Cocaine Self-Administration Apparatus}

For cue- and cocaine-induced reinstatement experiments, we used Imetronic experimental chambers equipped with nose-pokes as operanda and controlled by Imetronic interfaces and software (Imetronic, Pessac, France; www. imetronic.com). As stress-induced reinstatement of drug seeking is more easily obtained using lever-press responding (Drs Yavin Shaham and Taco De Vries, personal communication), for stress-induced reinstatement

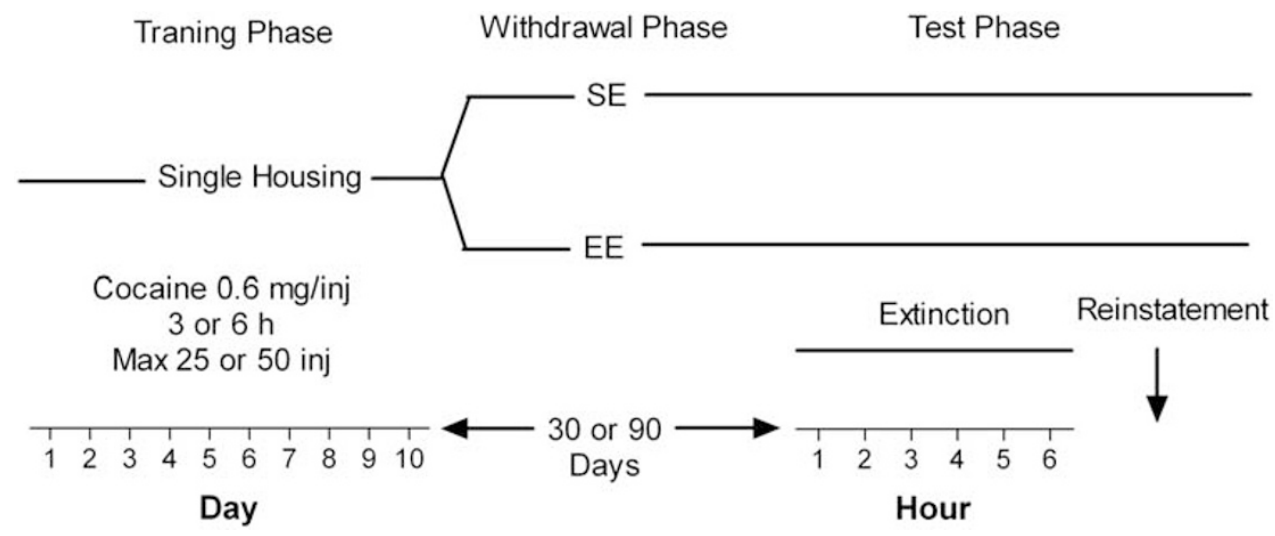

Figure I Schematic representation of the experimental procedures. During the training phase, rats were singly housed and 10 cocaine self-administration sessions were conducted during which they could self-administer cocaine $(0.6 \mathrm{mg} /$ injection). For experiments $1,2,3$, and 5 (Figures $2,3,4$, and 6$)$ session length was $6 \mathrm{~h}$, whereas for experiment 4 (Figure 5 ) it was reduced to $3 \mathrm{~h}$. The maximum number of injections was limited at 50 for $6 \mathrm{~h}$ session and to 25 for $3 \mathrm{~h}$ session. At the end of the last cocaine self-administration session, rats were assigned to standard environment (SE) or enriched environment (EE) conditions, assuring that two groups had similar levels of exposure to cocaine. During the withdrawal period, rats were housed three per cage in SE or EE in the animal facility. For experiments I, 2, 3, and 4 (Figures 2, 3, 4, and 5), rats were kept abstinent for 30 days before reinstatement testing, whereas for experiment 5 (Figure 6), abstinence lasted for 90 days. At the end of the withdrawal period, on the same day, rats were subjected to one 6-h extinction session and, subsequently, to one or two I-h reinstatement sessions (test phase). 
experiments, we used Coulbourn experimental chambers that were kindly donated by the National Institute on Drug Abuse and were equipped with retractable levers as operanda and controlled by Coulbourn interfaces and Graphic State software (Coulbourn Instruments, Allentown, PA, USA; www.coulbourn.com).

\section{Cocaine Self-Administration Procedure}

Ten cocaine self-administration sessions were conducted using a Fixed-Ratio 1 schedule of reinforcement. During daily sessions, a single response in the active nose-poke hole immediately delivered an i.v. injection of cocaine $(0.6 \mathrm{mg} /$ injection) and caused the house light to pulse for $5 \mathrm{~s}$ followed by a 5-s time-out. During this 5-s time-out period, the chambers were dark and responding had no programmed consequences. For experiments involving lever-press responding, conditions were similar but active lever-presses also resulted in retraction of the lever and delivery of the light plus tone stimuli. Responses in the inactive nose-poke hole or on the inactive lever were recorded but had no programmed consequences. Selfadministration sessions lasted for $6 \mathrm{~h}$ in all experiments, except experiment 4 in which 3-h sessions were used.

\section{Extinction of Cocaine Self-Administration and Cocaine Seeking}

After 30 or 90 days in either SE or EE housing conditions, rats were brought to the self-administration room and tested for extinction. For cue-induced reinstatement experiments, nose-pokes in the active or inactive hole during extinction sessions were recorded but had no programmed consequences. For all other experiments, active nose-pokes or active lever-presses during extinction sessions produced the same stimuli (light or light/tone and noise of the pump) that were earlier produced during cocaine self-administration sessions but syringes were removed from the injection pumps and cocaine was not delivered. The 6-h extinction session was divided into six 1-h extinction segments. The number of active nose-pokes or lever-presses was used as a measure of cocaine seeking.

\section{Cue-Induced Reinstatement}

In cue-induced reinstatement tests, the presentation of conditioned stimuli (light and pump noise) was made contingent on active nose-pokes, as it was during cocaine self-administration sessions. A single $1 \mathrm{~h}$ cue-induced reinstatement session was conducted immediately after the extinction session.

\section{Stress-Induced Reinstatement}

For stress-induced reinstatement experiments, saline $(1 \mathrm{ml} / \mathrm{kg}$ i.p.) was injected immediately before the fifth and sixth hour of the extinction session to allow adaptation to stress effects because of injection manipulations. A single $1 \mathrm{~h}$ stress-induced reinstatement session was conducted immediately after the extinction session. Immediately before the stress-induced reinstatement test session, rats were injected with yohimbine $(1.25 \mathrm{mg} / \mathrm{kg}$ i.p.). The $1.25 \mathrm{mg} / \mathrm{kg}$ dose of yohimbine was chosen on the basis of earlier studies showing that this dose reliably induces reinstatement in rats (Shepard et al, 2004; Lee et al, 2004; Lê et al, 2005; Feltenstein and See, 2006; Ghitza et al, 2006; Kupferschmidt et al, 2009).

\section{Cocaine-Induced Reinstatement}

For cocaine-induced reinstatement experiments, saline ( $1 \mathrm{ml} / \mathrm{kg}$ i.p.) was injected immediately before the fifth and sixth hour of the extinction session to allow adaptation to stress effects because of injection manipulations. Immediately after the extinction session, two consecutive $1 \mathrm{~h}$ cocaine-induced reinstatement sessions were conducted for experiments 3 and 4 by administering increasing doses of cocaine ( 3 and $6 \mathrm{mg} / \mathrm{kg}$ i.p.). A single $1 \mathrm{~h}$ cocaine-induced reinstatement session was conducted for experiments 5 with a cocaine dose of $6 \mathrm{mg} / \mathrm{kg}$. In an attempt to magnify possible positive effects of $\mathrm{EE}$ on cocaine-induced reinstatement, we chose low doses of cocaine that reliably induce reinstatement in rats (Lu et al, 2004a).

\section{Between-Day Procedure for Extinction and Reinstatement}

For this experiment (Figure 7), rats underwent selfadministration training with nose-pokes as operanda as described earlier. At the end of the training, rats were assigned to SE or EE conditions and, approximately $18 \mathrm{~h}$ later, daily 3 -h extinction sessions began for 10 consecutive days. On the 9th and 10th day of extinction, saline $(1 \mathrm{ml} / \mathrm{kg}$ i.p.) was injected immediately before the extinction session to allow adaptation to stress effects because of injection manipulations. Subsequently, on the 11th day, rats were injected with a cocaine dose of $6 \mathrm{mg} / \mathrm{kg}$ and cocaineinduced reinstatement was monitored in a single 3-h session.

\section{Drugs}

Cocaine $\mathrm{HCl}$ was purchased from the COOPER (Cooperation Pharmaceutique Francaise, France; www.cooper.fr). Drugs were dissolved in sterile saline solutions $(0.9 \%)$.

\section{Statistical Analysis}

Differences in drug-seeking behavior and reinstatement were assessed by two-way or three-way ANOVA for repeated measures. For incubation of craving, differences were assessed by two-way ANOVA. Results showing significant overall changes were subjected to StudentNewman-Keuls post hoc test. Differences were considered significant when $p<0.05$.

\section{RESULTS}

\section{Self-Administration of Cocaine Before Assignment to SE or EE}

For all experiments, rats were assigned to SE or EE at the end of the last cocaine self-administration session assuring that the two groups had similar basal levels of cocaine 
self-administration. Therefore, for each experiment, the number of active and inactive responses (Figures 2a, 3a, $4 a, 5 a$, and 6a) and the number of cocaine injections (Supplementary Figure 1) did not differ between future SE and future EE groups (see Supplementary Materials for detailed statistical analysis).

\section{Experiment 1: EE Reduces Cocaine Seeking and Cue-Induced Reinstatement}

In extinction sessions performed in the absence of conditioned cues (lights and pump noise), both SE $(n=10)$ and $\mathrm{EE}(n=10)$ rats showed a clear preference for the nose-poke hole compared with the inactive hole and drug-seeking behavior in both SE and EE rats extinguished within the 6-h session. However, drug seeking, measured as the number of active nose-pokes, was significantly lower in EE compared with SE rats (Figure $2 b$ and c). Statistical analysis revealed a significant effect of Environment $\left(\mathrm{F}_{1,18}=7.92, p<0.05\right)$, of Time $\left(\mathrm{F}_{5,95}=48.10, p<0.0001\right)$, of Active Device $\left(\mathrm{F}_{1,18}=40.44, p<0.0001\right)$, and a Time $\times$ Active Device interaction $\left(\mathrm{F}_{5,90}=18.41, p<0.0001\right)$.

In reinstatement sessions, when presentation of conditioned cues was made contingent on active nose-poking, both SE and EE rats reinstated cocaine seeking. However, cue-induced reinstatement was significantly lower in EE compared with SE rats (Figure 2d). Statistical analysis revealed a significant effect of Environment $\left(\mathrm{F}_{1,18}=15.53\right.$, $p<0.01)$, of Active Device $\left(\mathrm{F}_{1,18}=60.26, p<0.0001\right)$, and an Environment $X$ Active Device interaction $\left(\mathrm{F}_{1,18}=9.74\right.$, $p<0.01)$.

\section{Experiment 2: EE Reduces Cocaine Seeking and Stress-Induced Reinstatement}

In extinction sessions, both SE $(n=9)$ and $\mathrm{EE}(n=8)$ rats showed a clear preference for the active lever compared with the inactive lever and drug-seeking behavior in both SE and $\mathrm{EE}$ rats extinguished within the 6-h session. However, drug seeking, measured as the number of active leverpresses, was significantly lower in EE compared with SE rats (Figure $3 \mathrm{~b}$ and $\mathrm{c}$ ). Statistical analysis revealed a significant effect of Environment $\left(\mathrm{F}_{1,15}=7.01, p<0.05\right)$, of Time $\left(\mathrm{F}_{5,75}=55.89, p<0.0001\right)$, of Active Device $\left(\mathrm{F}_{1,15}=39.64\right.$, $p<0.0001)$, an Environment $\times$ Time interaction $\left(\mathrm{F}_{5,75}=\right.$ 4.37, $p<0.05)$, an Environment $\mathrm{X}$ Active Device interaction $\left(\mathrm{F}_{1,15}=14.19, p<0.01\right)$, a Time $\times$ Active Device interaction $\left(\mathrm{F}_{5,75}=85.73, p<0.0001\right)$, and an Environment $\times$ Time $\times$ Active Device interaction $\left(\mathrm{F}_{5,75}=5.72, p<0.01\right)$.

When the pharmacological stressor yohimbine $(1.25 \mathrm{mg} / \mathrm{kg}$ i.p.) was injected immediately before the reinstatement session, both SE and EE rats reinstated cocaine seeking.
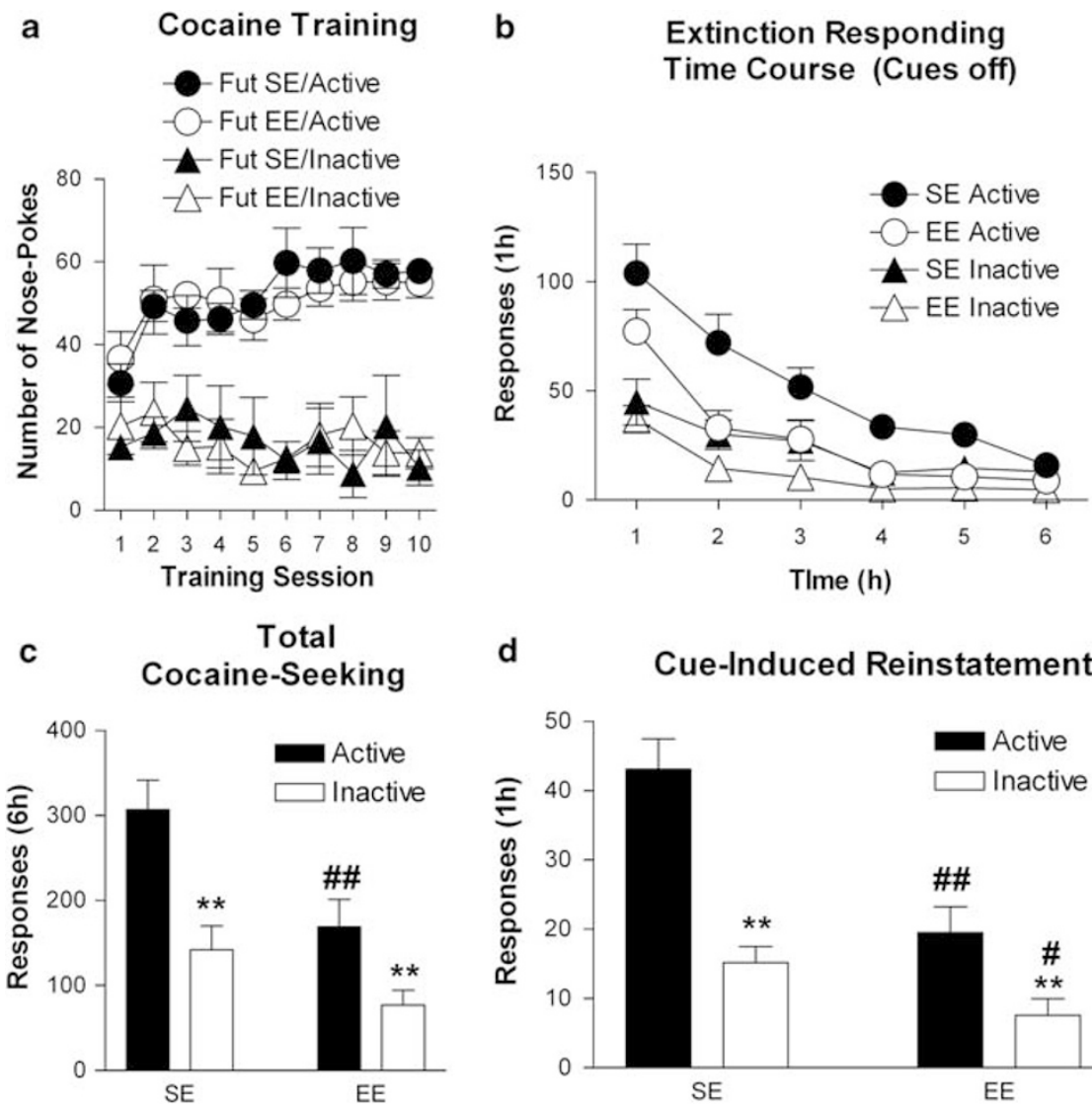

d
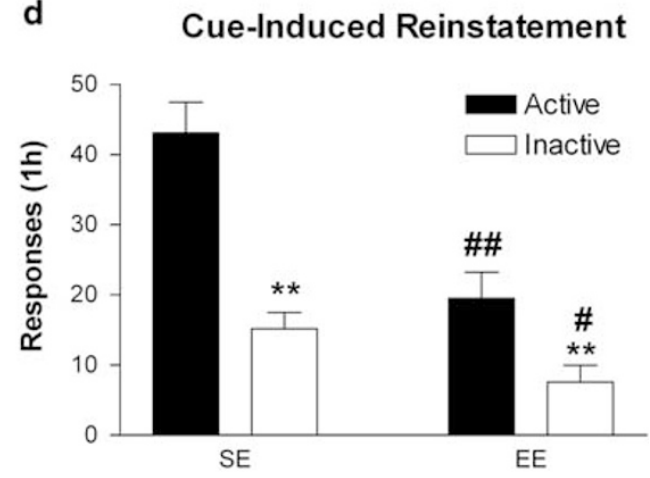

Figure 2 Effects of environmental enrichment on cue-induced reinstatement. Basal level of self-administration (a), time course of extinction (b), total cocaine seeking during extinction (c), and cue-induced reinstatement (d) in rats housed in standard environments (SE) or enriched environments (EE) during a 30-day abstinence period. Two-way ANOVA for repeated measures followed by post hoc Student-Newman-Keuls test: *** $<0.0$ I vs compared with active nose-poke; ${ }^{\# \#} p<0.0$ I vs compared with SE control. 
a

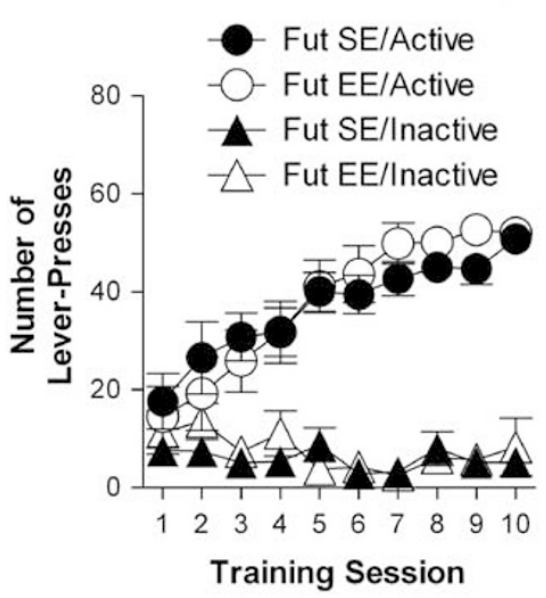

c

Total Cocaine-Seeking

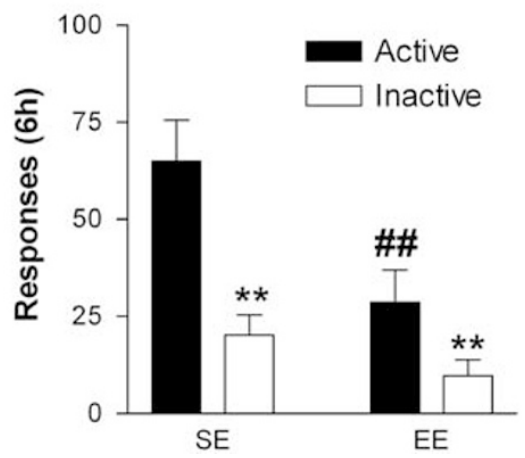

b
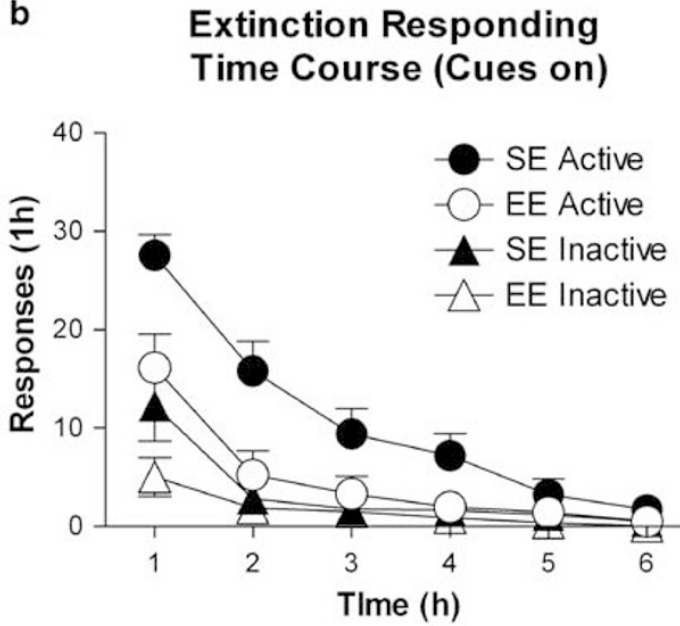

d

Yohimbine-Induced Reinstatement

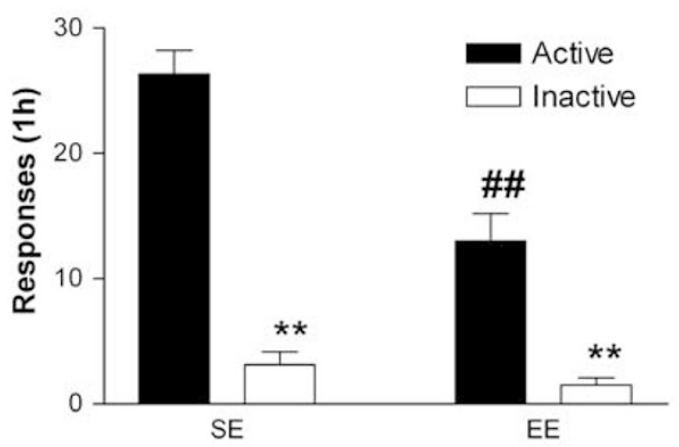

Figure 3 Effects of environmental enrichment on stress-induced reinstatement. Basal level of self-administration (a), time course of extinction (b), total cocaine seeking during extinction (c), and stress-induced reinstatement (d) in rats housed in standard environments (SE) or enriched environments (EE) during a 30-day abstinence period. Note that immediately before the fifth and sixth hour of extinction, rats were administered saline (I ml/kg). Reinstatement was triggered by administration of the pharmacological stressor yohimbine ( $1.25 \mathrm{mg} / \mathrm{kg}$ i.p.). Two-way ANOVA for repeated measures followed by post hoc Student-Newman-Keuls test: ${ }^{*} p<<0.01$ vs active nose-poke; ${ }^{\# \#} p<0.01$ vs SE control.

However, stress-induced reinstatement was significantly lower in EE compared with SE rats (Figure 3d). Statistical analysis revealed a significant effect of Environment $\left(\mathrm{F}_{1,15}=19.01, p<0.01\right)$, of Active Device $\left(\mathrm{F}_{1,15}=146.29\right.$, $p<0.0001)$, and an Environment $\mathrm{X}$ Active Device interaction $\left(\mathrm{F}_{1,15}=16.67, p<0.01\right)$.

\section{Experiment 3: EE Reduces Cocaine Seeking but Not Cocaine-Induced Reinstatement}

In extinction sessions performed in the presence of conditioned cues, both SE $(n=10)$ and EE $(n=11)$ rats showed a clear preference for the active nose-poke hole compared with the inactive hole and drug-seeking behavior in both SE and EE rats extinguished within the 6-h session. However, drug seeking was significantly lower in EE compared with SE rats (Figure $4 \mathrm{~b}$ and $\mathrm{c}$ ). Statistical analysis revealed a significant effect of Environment $\left(\mathrm{F}_{1,19}=8.96\right.$, $p<0.01)$, of Time $\left(\mathrm{F}_{5,95}=48.11, p<0.0001\right)$, of Active Device $\left(\mathrm{F}_{1,19}=41.98, p<0.0001\right)$, and a Time $\times$ Active Device interaction $\left(\mathrm{F}_{5,95}=11.78, p<0.0001\right)$.

When cocaine (3 or $6 \mathrm{mg} / \mathrm{kg}$ i.p.) was injected immediately before the reinstatement session, both SE and EE rats reinstated cocaine seeking. Surprisingly, cocaine-induced reinstatement was similar in EE and SE rats regardless of the cocaine dose (Figure $4 \mathrm{~d}$ ). Statistical analysis revealed a significant effect of Active Device $\left(\mathrm{F}_{1,18}=40.10, p<0.0001\right)$, of Dose $\left(\mathrm{F}_{1,18}=19.78, p<0.01\right)$, and an Active Device $\times$ Dose interaction $\left(\mathrm{F}_{1,18}=11.97, p<0.01\right)$.

Experiment 4: The Lack of Effects of EE on CocaineInduced Reinstatement Does Not Depend on the Level of Cocaine Exposure

As we had found earlier that cocaine-induced reinstatement of an extinguished CPP in mice was prevented by EE (Solinas et al, 2008), we were surprised by the lack of effect of EE on cocaine-induced reinstatement of drug seeking in this study. Therefore, we designed a series of manipulations to rule out the possibility that differences in the experimental procedures may have masked the positive effects of $\mathrm{EE}$ in the present experiments.

First, we investigated whether our cocaine self-administration procedure had rendered rats too 'addicted' for EE to produce its effects by reducing the cocaine $(0.6 \mathrm{mg} /$ injection) self-administration sessions to $3 \mathrm{~h}$ instead of $6 \mathrm{~h}$ 
a
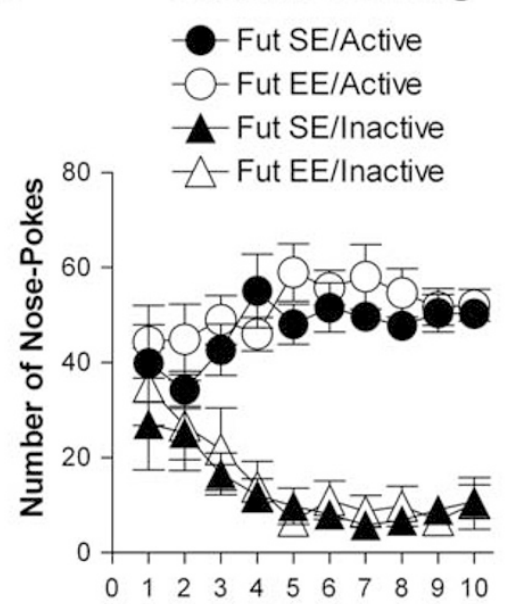

Training Session

C
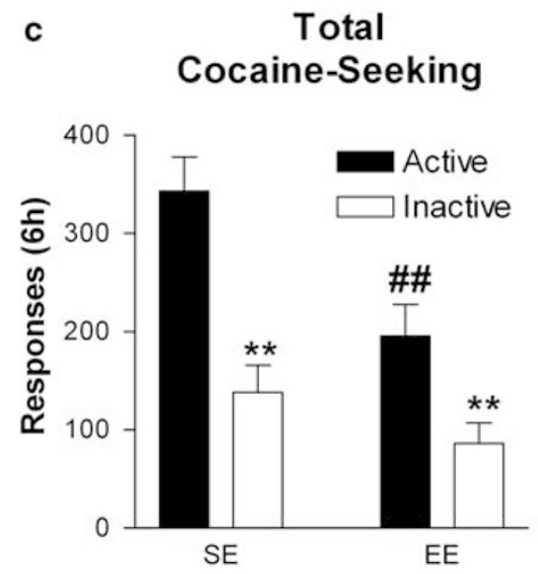

b

Extinction Responding

Time Course (Cues on)

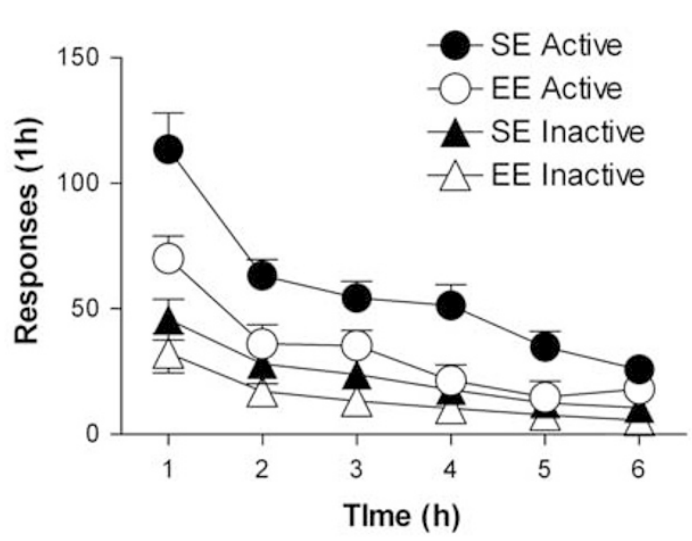

d

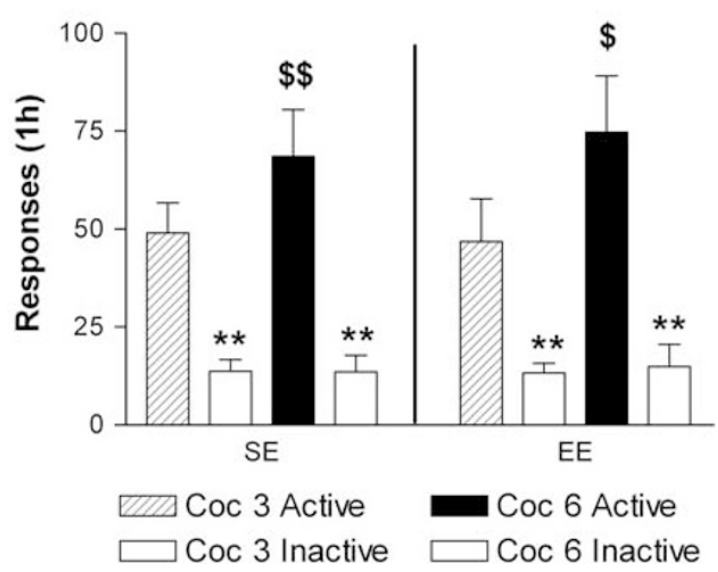

Cocaine-induced Reinstatement

Figure 4 Effects of environmental enrichment on cocaine-induced reinstatement in rats with $6 \mathrm{~h}$ access to cocaine. Basal level of self-administration (a), time course of extinction (b), total cocaine seeking during extinction (c), and cocaine-induced reinstatement (d) in rats housed in standard environments (SE) or enriched environments (EE) during a 30-day abstinence period. Note that immediately before the fifth and sixth hour of extinction, rats were administered saline $(\mathrm{I} \mathrm{ml} / \mathrm{kg}$ ). Reinstatement was triggered by administration of cocaine (3 and $6 \mathrm{mg} / \mathrm{kg}$ i.p.). Two-way ANOVA for repeated measures followed by post hoc Student-Newman-Keuls test: ${ }^{*} * p<0.01$ vs active nose-poke; ${ }^{\# \#} p<0.01$ vs SE control; ${ }^{\$ \$ \$} p<0.05$ and 0.01 vs cocaine $3 \mathrm{mg} / \mathrm{kg}$.

for 10 consecutive days before assigning rats to $\mathrm{SE}$ or $\mathrm{EE}$ housing conditions. Consistent with the other self-administration experiments, during extinction sessions, both SE $(n=7)$ and $\mathrm{EE}(n=8)$ rats showed a clear preference for the active nose-poke hole and drug-seeking behavior in both SE and $\mathrm{EE}$ rats extinguished within the 6-h session. However, drug seeking was significantly lower in EE compared with SE rats (Figure $5 \mathrm{a}$ and $\mathrm{b}$ ). Statistical analysis revealed a significant effect of Environment $\left(\mathrm{F}_{1,13}=8.88, p<0.05\right)$, of Time $\left(\mathrm{F}_{5,65}=47.11, p<0.01\right)$, of Active Device $\left(\mathrm{F}_{1,13}=29.25\right.$, $p<0.0001)$, and a Time $\times$ Active Device interaction $\left(\mathrm{F}_{5,65}=9.22, p<0.0001\right)$.

In addition, similar to what was found with $6 \mathrm{~h}$ cocaine self-administration sessions, cocaine-induced reinstatement was similar in EE and SE rats that had self-administered cocaine during the 3 -h sessions, regardless of the cocaine dose (Figure $5 \mathrm{c}$ ). Statistical analysis revealed a significant effect of Active Device $\left(\mathrm{F}_{1,13}=8.72, p<0.05\right)$ and of Dose $\left(\mathrm{F}_{1,13}=33.00, p<0.0001\right)$.
Experiment 5: The Lack of Effects of EE on Cocaine-Induced Reinstatement Does Not Depend on the Duration of EE

As a second step, we investigated whether a longer period of EE was necessary for EE to produce its effects on cocaineinduced reinstatement. After the 10 sessions of cocaine selfadministration, rats were separated into SE or EE housing conditions and were then kept abstinent for 90 instead of 30 days. Once again, in extinction sessions, both SE $(n=4)$ and EE $(n=5)$ rats showed a preference for the active nosepoke hole and drug-seeking behavior in both SE and EE rats extinguished within the 6-h session. Again, drug seeking was significantly lower in EE compared with SE rats (Figure $6 \mathrm{a}$ and $\mathrm{b})$. Statistical analysis revealed a significant effect of Environment $\left(\mathrm{F}_{1,7}=17.78, p<0.01\right)$, of Time $\left(\mathrm{F}_{5,35}=34.11\right.$, $p<0.0001)$, an Environment $\times$ Time interaction $\left(\mathrm{F}_{5,35}=\right.$ 2.88, $p<0.05)$, and a Time $\times$ Active Device interaction $\left(\mathrm{F}_{5,35}=3.11, p<0.05\right)$. 
a

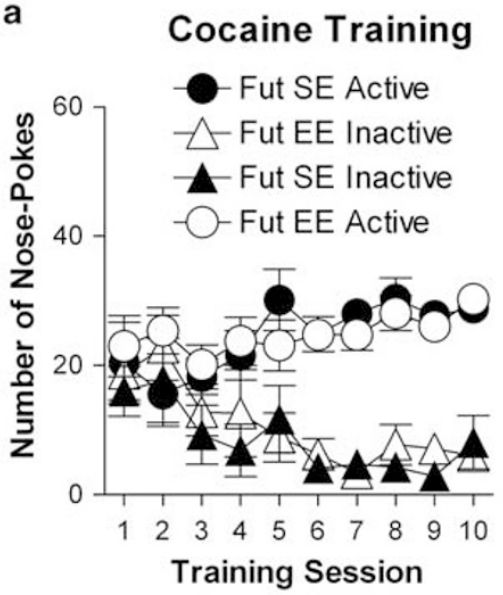

C

Total Cocaine-Seeking

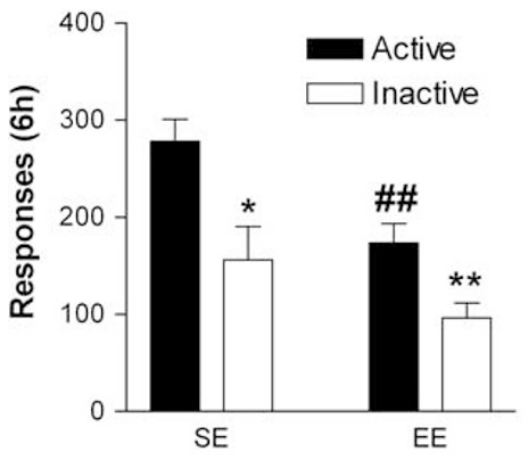

b

Extinction Responding Time Course (Cues on)

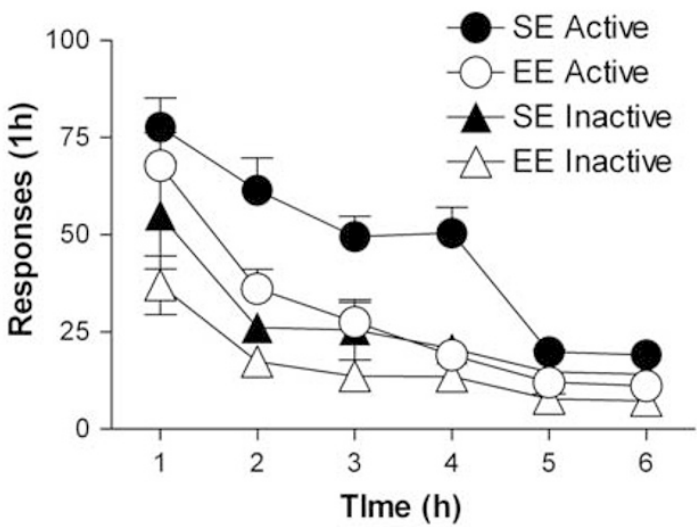

d

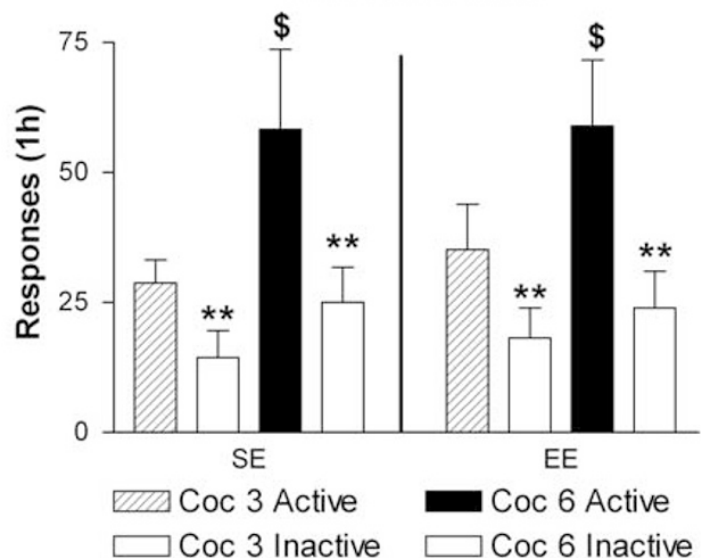

Figure 5 Effects of environmental enrichment on cocaine-induced reinstatement in rats with $3 \mathrm{~h}$ access to cocaine. Basal level of self-administration (a), time course of extinction (b), total cocaine seeking during extinction (c), and cocaine-induced reinstatement (d) in rats housed in standard environments (SE) or enriched environments (EE) during a 30-day abstinence period. In this experiment, rats self-administered cocaine for $3 \mathrm{~h}$ instead of $6 \mathrm{~h}$ for 10 days before the abstinence period. Note that immediately before the fifth and sixth hour of extinction, rats were administered saline (I ml/kg). Reinstatement was triggered by administration of cocaine ( 3 and $6 \mathrm{mg} / \mathrm{kg}$ i.p.). Two-way ANOVA for repeated measures followed by post hoc Student-Newman-Keuls test: ${ }^{*} \cdot * * * 0.05$ and 0.01 vs active nose-poke; ${ }^{\# \#} p<0.01$ vs SE control.; ${ }_{p}<0.05$ vs cocaine $3 \mathrm{mg} / \mathrm{kg}$.

In addition, similar to what was found in rats kept abstinent in their respective environmental condition for 30 days, in rats housed in EE and SE for 90 days, cocaineinduced reinstatement was similar (Figure 6c). Statistical analysis revealed only a significant effect of Active Device $\left(\mathrm{F}_{1,7}=7.34, p<0.05\right)$.

\section{Experiment 6: EE Does Not Attenuate Cocaine-Induced Reinstatement in a Between-Day Procedure of Extinction and Reinstatement}

In our earlier study in mice with CPP procedures, 10 extinction sessions and one reinstatement session were performed over an 11-day period (Solinas et al, 2008). To determine whether these procedural differences in extinction conditions might be responsible for the lack of effects of $\mathrm{EE}$ on cocaine-induced reinstatement of drug seeking, we used a similar extinction procedure in rats that had selfadministered cocaine. Thus, immediately after the last day of cocaine self-administration, rats were housed in SE $(n=8)$ or EE $(n=8)$ conditions and, approximately $18 \mathrm{~h}$ later, daily $3 \mathrm{~h}$ extinction sessions began. Extinction of cocaine seeking was faster and more pronounced in EE than compared with SE rats, even when they were in the EE for $<24 \mathrm{~h}$ (Figure 7a) but once again, cocaine-induced reinstatement was similar between SE and EE rats (Figure 7b).

\section{DISCUSSION}

In these experiments, we found that exposure to EE during long periods of abstinence from cocaine self-administration consistently reduces drug seeking and attenuates reinstatement induced by conditioned cues and stress. On the other hand, reinstatement induced by experimenter-administered cocaine was not altered by EE under a variety of experimental conditions. These results suggest that EE can reduce the risks of relapse to cocaine addiction but also 


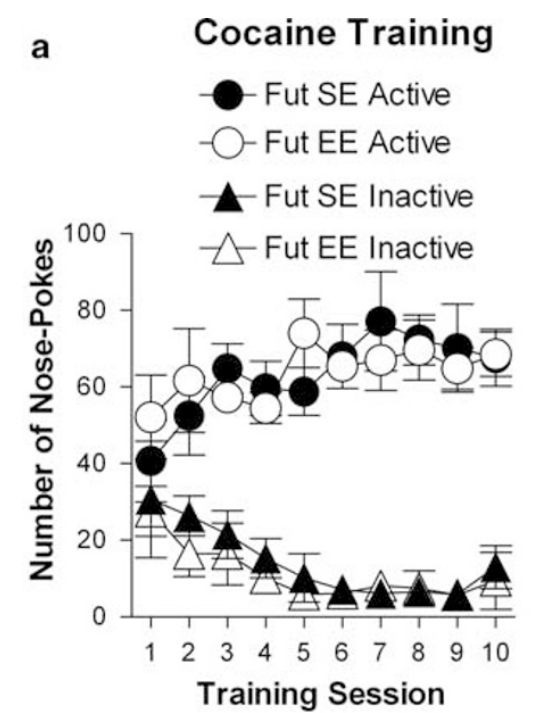

\section{b Extinction Responding Time Course (Cues on)}

c

Total Cocaine-Seeking

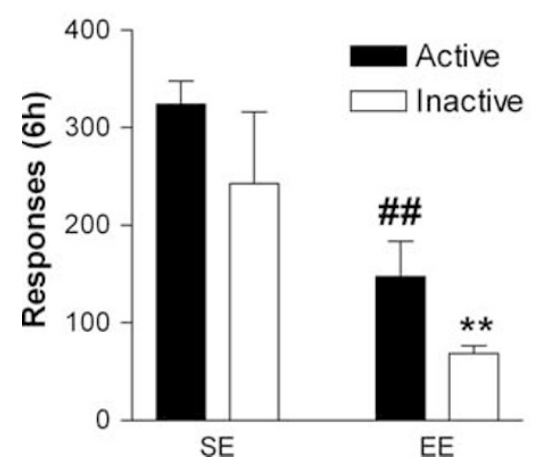

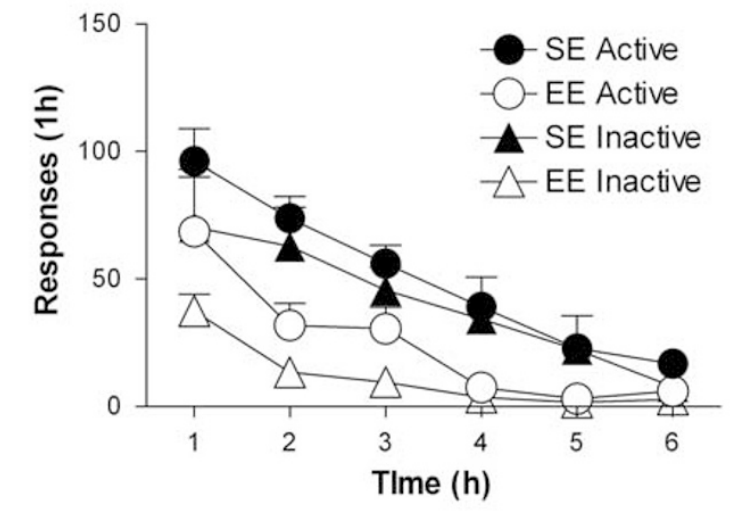

d

\section{Cocaine-induced Reinstatement}

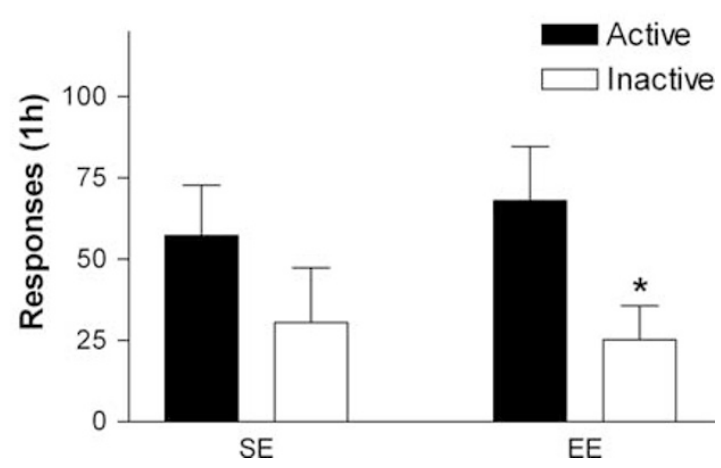

Figure 6 Effects of 90 days of environmental enrichment on cocaine-induced reinstatement. Basal level of self-administration (a), time course of extinction (b), total cocaine seeking during extinction (c), and cocaine-induced reinstatement (d) in rats housed in standard environments (SE) or enriched environments (EE). In this experiment, the abstinence period and the exposure to SE or EE was increased to 90 days. Note that immediately before the fifth and sixth hour of extinction, rats were administered saline $(\mathrm{I} \mathrm{ml} / \mathrm{kg})$. Reinstatement was triggered by administration of cocaine $(6 \mathrm{mg} / \mathrm{kg}$ i.p.). Two-way ANOVA for repeated measures followed by post hoc Student-Newman-Keuls test: ${ }^{* * * *} p<0.05$ and 0.0 I vs active nose-poke; ${ }^{\# \#} p<0.0$ I vs SE control.

point out to the fact that exposure to earlier abused drugs may overcome the protection provided by EE.

In the last decades, several studies have shown that $\mathrm{EE}$ conditions potentiate cognitive functions (for review see Rosenzweig and Bennett 1996; van Praag et al, 2000) and can protect the brain against neurological and neurodegenerative disorders (Nithianantharajah and Hannan 2006; Laviola et al, 2008). In addition, EE conditions influence the behavioral and neurochemical effects of drug abuse and may provide protection against the development of drug addiction (Bardo et al, 2001; Carroll et al, 2009; El Rawas et al, 2009; Jessor and Jessor 1980; Solinas et al, 2009; Stairs and Bardo 2009). Although earlier studies had focused on the preventive effects of $\mathrm{EE}$, we have recently shown that $\mathrm{EE}$ can also have 'curative' effects on cocaine addiction (Solinas et al, 2008). In addition, Grimm et al (2008) have recently reported that craving for food is also reduced by exposure to EE during periods of withdrawal (Grimm et al, 2008). Similarly, in this study, we found that cocaine seeking during extinction sessions was reduced in each of our experiments, regardless of the operanda used (nose-poke or lever-press), the presence or absence of conditioned stimuli, the level of earlier cocaine exposure $(3$ or $6 \mathrm{~h}$ selfadministration sessions), and the duration of exposure to EE during abstinence (30 or 90 days). Altogether, these findings strongly support the hypothesis that $\mathrm{EE}$ have significant beneficial effects on cocaine addiction.

Once cocaine-seeking behavior was extinguished, we were able to reinstate cocaine seeking by exposing animals to conditioned cues, to an experimenter-administered dose of cocaine or to the pharmacological stressor yohimbine (de Wit and Stewart 1981; Epstein et al, 2006; Shalev et al, 2002). Yohimbine is a drug with a mixed pharmacological profile. In fact, although its best-characterized mechanism of action is the blockade of $\alpha-2$ noradrenergic and the increase in noradrenergic cell firing and release (Aghajanian and VanderMaelen, 1982; Abercrombie et al, 1988), it has also been shown to bind to serotonin and dopamine receptors and to increase the activity of dopamine systems (Millan et al, 2000; Tanda et al, 1996). Yohimbine causes anxiety-like symptoms in humans and animals (Bremner et al, 1996a; Bremner et al, 1996b) and induces reinstatement 
a

\section{Extinction of cocaine seeking}

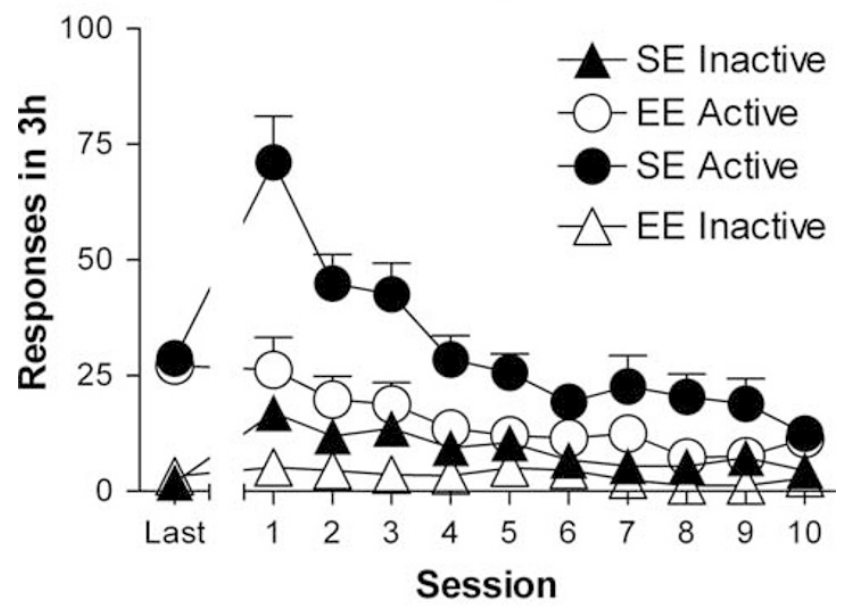

b

\section{Cocaine-Induced Reinstatement}

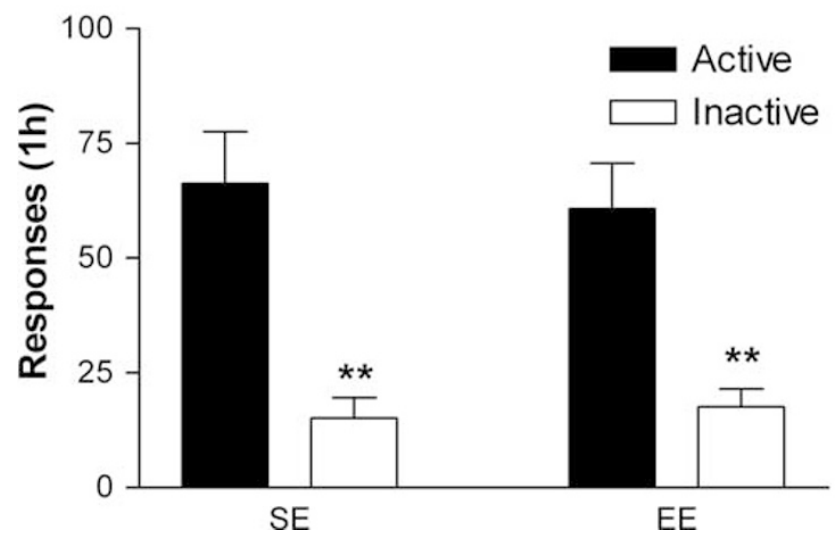

Figure 7 Effects of environmental enrichment on cocaine-induced reinstatement in a between-day procedure of extinction and reinstatement. Number of active nose-pokes in the first $3 \mathrm{~h}$ of the last 6-h session of training (left part) and extinction of cocaine seeking in 10 consecutive 3-h sessions (a) in rats housed in standard (SE) or enriched environments (EE). Cocaine-induced reinstatement in SE and EE rats (b) during a single I-h reinstatement session on the day after the last day of extinction. Note that immediately before the 9th and I0th session of extinction, rats were administered with saline $(\mathrm{I} \mathrm{ml} / \mathrm{kg})$. Reinstatement was triggered by administration of the cocaine $(6 \mathrm{mg} / \mathrm{kg}$ i.p.). Two-way ANOVA for repeated measures followed by post hoc Student-Newman-Keuls test: ${ }^{*} p<0.05$ vs active nose-poke. ${ }^{*} * p<0.0$ I

of extinguished drug seeking in rats and this effect appears to be more robust than that induced by footshock, a nonpharmacological stressor commonly used in rodent research (Shepard et al, 2004; Lê et al, 2005; Ghitza et al, 2006). Therefore, the use of yohimbine as a pharmacological stressor in reinstatement procedures has become increasingly popular (Shepard et al, 2004; Lee et al, 2004; Lê et al, 2005; Feltenstein and See, 2006; Ghitza et al, 2006; Kupferschmidt et al, 2009). Importantly, EE was able to significantly reduce reinstatement induced by contextual cues and stress. Given that exposure to conditioned cues, and stressful situations appear to be powerful triggers of relapse in humans (Epstein et al, 2009), this suggests that environmental stimulation during periods of abstinence may be an important factor in decreasing the risks of relapse.

On the other hand, EE did not alter cocaine-induced reinstatement. The finding that a single manipulation (exposure to $\mathrm{EE}$ in this case) affects different forms of reinstatement differently is not uncommon (see Shalev et al, 2002 for review). For example, cocaine craving as measured by responding during extinction and cue-induced reinstatement increase over time, whereas cocaine-induced reinstatement does not (Grimm et al, 2001; Lu et al, 2004a). Given our earlier findings obtained in mice with CPP procedure (Solinas et al, 2008), it was unexpected that cocaine-induced reinstatement was not blocked by EE. Therefore, we performed a series of manipulations to exclude the possibility that differences in experimental procedures were responsible for this lack of effect. We found that the lack of effect of $\mathrm{EE}$ on cocaine-induced reinstatement was not due to of the level of cocaine exposure (ie, the rats were not too 'addicted'), nor to the duration of exposure to the EE (ie, 30 and 90 days of EE had similar effects on cocaine seeking). This discrepancy may be explained by differences in species or differences in the underlying behavior measured by self-administration $v s$ CPP procedures (Bardo and Bevins 2000; Sanchis-Segura and Spanagel, 2006). Notwithstanding these differences, our self-administration data suggest that pharmacological stimulation of the brain by cocaine may overcome the protection provided by EE. However, given that cocaine administration generally follows a voluntary act in humans (Epstein et al, 2006), our data on cocaine seeking during extinction and cue- and stress-induced reinstatement indicate that stimulating environments may be powerful factors in facilitating abstinence and reducing the risks of relapse.

The mechanisms through which EE could reduce cocaine seeking and reinstatement are yet to be determined. Loss of cocaine memories does not seem to be a likely mechanism because the same EE rats that show consistent reductions in drug seeking during extinction sessions show drug seeking similar to SE rats after administration of cocaine, suggesting that memories of cocaine remain intact in EE rats. A wellknown effect of EE is to increase learning (for review see Rosenzweig and Bennett, 1996; van Praag et al, 2000). On the basis of these results, Grimm et al (2008) suggested that $\mathrm{EE}$ rats learn faster in extinction that their actions are not rewarded and, therefore, quit responding earlier than SE controls. Alternatively, EE could have made cocaine-related stimuli less salient and rats could have been less motivated to respond for them. EE has been also shown to decrease impulsivity in rats (Hellemans et al, 2005; Perry et al, 2008). As impulsivity has been shown to be associated with high risks of relapse (Economidou et al, 2009; Lê et al, 2008; Perry et al, 2008), it could also be speculated that positive effects of $\mathrm{EE}$ on cocaine seeking and cue- and stressinduced reinstatement are mediated by decreases in impulsivity. Psychostimulant addiction appears to be associated with deficits in decision making and other cognitive tasks such as behavioral inflexibility and perseverative behaviors that may have an important function in relapse (Verdejo-García and Bechara, 2009; Stalnaker et al, 2009; Ersche et al, 2009). Therefore, EE may have acted by reversing these cocaine-induced deficits. 
Stress can have marked influences on motivated behaviors. For example, acute stress increases the reactivity to rewards and precipitates reinstatement of extinguished drug seeking (Goeders, 2003; Shalev et al, 2002). On the other hand, chronic stress has been reported to decrease (Willner, 2005; Matthews and Robbins, 2003) or increase (Goeders, 2003; Carr, 2002; Koob and Kreek, 2007; Miczek et al, 2008) the reactivity to rewards depending on the intensity, the duration, and the type of stressor applied. In particular, exposure to chronic unpredictable mild stress or to repeated maternal separation produces a depression-like phenotype that is associated with reduction in the reinforcing effects of sucrose and of psychostimulants (Willner, 2005; Matthews and Robbins, 2003). In contrast, chronic food restriction, repeated incontrollable foot-shock and social defeat increase the rewarding effects of drugs and/or of intracranial self-stimulation (Carr, 2002; Goeders, 2003; Koob and Kreek, 2007; Miczek et al, 2008). Exposure to EE prevents and reverses the behavioral and neurochemical consequences of the exposure to stressors (Laviola et al, 2008). Therefore, one important mechanism that could underlie the positive effects of EE is its antistress effects. This hypothesis is supported by our earlier findings in mice showing that EE decreased behavioral sensitization, whereas stress (social isolation) increased it (Solinas et al, 2008). In addition, the finding that EE reduces reinstatement induced by a pharmacological stressor are also in favor of this hypothesis. However, it should be noticed that in the present experiments rats were tested in extinction that is rats were not given the possibility to self-administer cocaine after the exposure to EE or SE conditions. Therefore, the modulation of the reinforcing effects of cocaine by stress cannot be responsible for the beneficial effects of $\mathrm{EE}$ on cocaine-seeking behavior. Indeed, our data on cocaineinduced reinstatement suggest that the motivational effects of cocaine are unaltered in EE rats. Thus, if EE produced its beneficial effects through an antistress effect, this would be achieved by reducing the ability of stress to facilitate responding for stimuli associated with cocaine (Goeders and Clampitt, 2002).

EE could also have reduced cocaine seeking and reinstatement through an antidepressant-like effect (Laviola et al, 2008). Consistent with this hypothesis, chronic administration of the antidepressant fluoxetine, like chronic exposure to EE, reduces the motivation to respond for cocaine-paired cues but has no effect on cocaine-induced reinstatement (Baker et al, 2001). Finally, other mechanisms, such as EE-induced hippocampal neurogenesis (van Praag et al, 2000) or chromatin rearrangement (Fischer et al, 2007; Pizzorusso et al, 2007; Sweatt 2009), could have a function in the positive effects of EE on cocaine addiction. Further studies are necessary to better define the neurobiological mechanisms underlying the effects of EE.

Quite unexpectedly, we found that rats housed in EE for $<24 \mathrm{~h}$ show faster extinction of cocaine-seeking behavior than rats housed in SE (Figure 7). However, it is quite unlikely that the aforementioned behavioral and neurobiological mechanisms produced by chronic EE (learning, neurogenesis, antistress effects, etc) could take place in such a short time and it is more likely that different mechanisms are responsible for this rapid effect. For example, it has been shown earlier that exposures to environmental enrichment for 3 and $6 \mathrm{~h}$ produce changes in gene expression in the cortex of mice that are qualitatively different from those of longer 14 days exposure (Rampon et al, 2000). Indeed, the effects of such a short exposure to EE could be due to several factors that we are not able to point out at the moment including exposure to novelty, stress, and physical activity. Although these results should not be confused with the effects of chronic environmental enrichment, they highlight the fact that EE can have a variety of effects that need to be better understood.

In conclusion, environmental stimulation facilitates abstinence and reduces the risks of relapse in rats. These results highlight how environmental conditions of people seeking to quit drug-taking may contribute to the successful outcome of their efforts. As recently discussed elsewhere, these preclinical results in animals are in agreement with human studies in which different forms of stimulation have been shown to be beneficial for the treatment of addiction. (Schnabel 2009; Setlow 2008). Therefore, the use of environmental stimulation together with pharmacological treatment and behavioral therapy may be of fundamental importance in the success of drug addiction treatment programs.

\section{ACKNOWLEDGEMENTS}

We thank $\mathrm{N}$ Thiriet and D Belin for their helpful discussion and NIDA/NIH for donation of the Coulbourn cages. This work was supported by Centre National pour la Recherche Scientifique, University of Poitiers, Mission Interministérielle de la Lutte contre les Drogues et la Toxicomanie (MILDT-INSERM, 2006-2007 and MILDT-INSERM-INCA 2007-2009), Région Poitou Charentes, and the Intramural Research Program of the National Institute on Drug Abuse, National Institutes of Health, Department of Health and Human Services, Baltimore, Maryland. C Chauvet is a recipient of a $\mathrm{PhD}$ fellowship from the French Ministry of Research.

\section{DISCLOSURE}

The authors declare that, except for income received from their primary employer, no financial support or compensation has been received from any individual or corporate entity over the past 3 years for research or professional service and there are no personal financial holdings that could be perceived as constituting a potential conflict of interests.

\section{REFERENCES}

Abercrombie ED, Keller Jr RW, Zigmond MJ (1988). Characterization of hippocampal norepinephrine release as measured by microdialysis perfusion: pharmacological and behavioral studies. Neuroscience 27: 897-904.

Aghajanian GK, VanderMaelen CP (1982). Alpha 2-adrenoceptormediated hyperpolarization of locus coeruleus neurons: intracellular studies in vivo. Science 215: 1394-1396.

Baker DA, Tran-Nguyen TL, Fuchs RA, Neisewander JL (2001). Influence of individual differences and chronic fluoxetine treatment on cocaine-seeking behavior in rats. Psychopharmacology (Berl) 155: 18-26. 
Bardo MT, Bevins RA (2000). Conditioned place preference: what does it add to our preclinical understanding of drug reward? Psychopharmacology (Berl) 153: 31-43.

Bardo MT, Klebaur JE, Valone JM, Deaton C (2001). Environmental enrichment decreases intravenous self-administration of amphetamine in female and male rats. Psychopharmacology (Berl) 155: 278-284.

Bremner JD, Krystal JH, Southwick SM, Charney DS (1996a). Noradrenergic mechanisms in stress and anxiety: I. preclinical studies. Synapse 23: 28-38.

Bremner JD, Krystal JH, Southwick SM, Charney DS (1996b). Noradrenergic mechanisms in stress and anxiety: II. clinical studies. Synapse 23: 39-51.

Carr KD (2002). Augmentation of drug reward by chronic food restriction: behavioral evidence and underlying mechanisms. Physiol Behav 76: 353-364.

Carroll ME, Anker JJ, Perry JL (2009). Modeling risk factors for nicotine and other drug abuse in the preclinical laboratory. Drug Alcohol Depend. doi:10.1016/J.drugakdep.2008.11.04

de Wit H, Stewart J (1981). Reinstatement of cocaine-reinforced responding in the rat. Psychopharmacology (Berl) 75: 134-143.

Economidou D, Pelloux Y, Robbins TW, Dalley JW, Everitt BJ (2009). High impulsivity predicts relapse to cocaine-seeking after punishment-induced abstinence. Biol Psychiatr 65: 851-856.

El Rawas R, Thiriet N, Lardeux V, Jaber M, Solinas M (2009). Environmental enrichment decreases the rewarding but not the activating effects of heroin. Psychopharmacology (Berl) 203: 561-570.

Ersche KD, Roiser JP, Robbins TW, Sahakian BJ (2009). Chronic cocaine but not chronic amphetamine use is associated with perseverative responding in humans. Psychopharmacology (Berl) 197: 421-431.

Epstein DH, Preston KL, Stewart J, Shaham Y (2006). Toward a model of drug relapse: an assessment of the validity of the reinstatement procedure. Psychopharmacology (Berl) 189: 1-16.

Epstein DH, Willner-Reid J, Vahabzadeh M, Mezghanni M, Lin JL, Preston KL (2009). Real-time electronic diary reports of cue exposure and mood in the hours before cocaine and heroin craving and use. Arch Gen Psychiatry 66: 88-94.

Feltenstein MW, See RE (2006). Potentiation of cue-induced reinstatement of cocaine-seeking in rats by the anxiogenic drug yohimbine. Behav Brain Res 174: 1-8.

Fischer A, Sananbenesi F, Wang X, Dobbin M, Tsai LH (2007). Recovery of learning and memory is associated with chromatin remodelling. Nature 447: 178-182.

Ghitza UE, Gray SM, Epstein DH, Rice KC, Shaham Y (2006). The anxiogenic drug yohimbine reinstates palatable food seeking in a rat relapse model: a role of CRF1 receptors. Neuropsychopharmacology 31: 2188-2196.

Goeders NE (2003). The impact of stress on addiction. Eur Neuropsychopharmacol 13: 435-441.

Goeders NE, Clampitt DM (2002). Potential role for the HPA axis in the conditioned reinforcer-induced reinstatement of extinguished cocaine seeking in rats. Psychopharmacology (Berl) 161: 222-232.

Grimm JW, Hope BT, Wise RA, Shaham Y (2001). Neuroadaptation. Incubation of cocaine craving after withdrawal. Nature 412: 141-142.

Grimm JW, Osincup D, Wells B, Manaois M, Fyall A, Buse C et al (2008). Environmental enrichment attenuates cue-induced reinstatement of sucrose seeking in rats. Behav Pharmacol 19: 777-785.

Jessor R, Jessor S (1980). A social-psychological framework for studying drug use. NIDA Res Monogr 30: 102-109.

Koob GF, Kreek MJ (2007). Stress, dysregulation of drug reward pathways, and the transition to drug dependence. $A m J$ Psychiatry 164: 1149-1159.
Kupferschmidt DA, Tribe E, Erb S (2009). Effects of repeated yohimbine on the extinction and reinstatement of cocaine seeking. Pharmacol Biochem Behav 91: 473-480.

Laviola G, Hannan AJ, Macri S, Solinas M, Jaber M (2008). Effects of enriched environment on animal models of neurodegenerative diseases and psychiatric disorders. Neurobiol Dis 31: 159-168.

Lê AD, Harding S, Juzytsch W, Funk D, Shaham Y (2005). Role of alpha-2 adrenoceptors in stress-induced reinstatement of alcohol seeking and alcohol self-administration in rats. Psychopharmacology (Berl) 179: 366-373.

Lề AD, Funk D, Harding S, Juzytsch W, Li Z, Fletcher PJ (2008). Intra-median raphe nucleus (MRN) infusions of muscimol, a GABA-A receptor agonist, reinstate alcohol seeking in rats: role of impulsivity and reward. Psychopharmacology (Berl) 195: 605-615.

Lee B, Tiefenbacher S, Platt DM, Spealman RD (2004). Pharmacological blockade of alpha2-adrenoceptors induces reinstatement of cocaine-seeking behavior in squirrel monkeys. Neuropsychopharmacology 29: 686-693.

Lu L, Grimm JW, Dempsey J, Shaham Y (2004a). Cocaine seeking over extended withdrawal periods in rats: different time courses of responding induced by cocaine cues versus cocaine priming over the first 6 months. Psychopharmacology (Berl) 176: 101-108.

Lu L, Grimm JW, Hope BT, Shaham Y (2004b). Incubation of cocaine craving after withdrawal: a review of preclinical data. Neuropharmacology 47(Suppl 1): 214-226.

Marinelli M, Piazza PV (2002). Interaction between glucocorticoid hormones, stress and psychostimulant drugs. Eur J Neurosci 16: 387-394.

Matthews K, Robbins TW (2003). Early experience as a determinant of adult behavioural responses to reward: the effects of repeated maternal separation in the rat. Neurosci Biobehav Rev 27: 45-55.

Miczek KA, Yap JJ, Covington HE (2008). Social stress, therapeutics and drug abuse: preclinical models of escalated and depressed intake. Pharmacol Ther 120: 102-128.

Millan MJ, Newman-Tancredi A, Audinot V, Cussac D, Lejeune F, Nicolas JP et al (2000). Agonist and antagonist actions of yohimbine as compared to fluparoxan at alpha(2)-adrenergic receptors $(\mathrm{AR}) \mathrm{s}$, serotonin $(5-\mathrm{HT})(1 \mathrm{~A}), 5-\mathrm{HT}(1 \mathrm{~B}), 5-\mathrm{HT}(1 \mathrm{D})$ and dopamine $\mathrm{D}(2)$ and $\mathrm{D}(3)$ receptors. Significance for the modulation of frontocortical monoaminergic transmission and depressive states. Synapse 35: 79-95.

Nithianantharajah J, Hannan AJ (2006). Enriched environments, experience-dependent plasticity and disorders of the nervous system. Nat Rev Neurosci 7: 697-709.

Hellemans KG, Nobrega JN, Olmstead MC (2005). Early environmental experience alters baseline and ethanol-induced cognitive impulsivity: relationship to forebrain 5-HT1A receptor binding. Behav Brain Res 159: 207-220.

Panlilio LV, Goldberg SR (2007). Self-administration of drugs in animals and humans as a model and an investigative tool. Addiction 102: 1863-1870.

Perry JL, Stairs DJ, Bardo MT (2008). Impulsive choice and environmental enrichment: effects of d-amphetamine and methylphenidate. Behav Brain Res 193: 48-54.

Perry JL, Nelson SE, Carroll ME (2008). Impulsive choice as a predictor of acquisition of IV cocaine self- administration and reinstatement of cocaine-seeking behavior in male and female rats. Exp Clin Psychopharmacol 16: 165-177.

Pizzorusso T, Berardi N, Maffei L (2007). A richness that cures. Neuron 54: 508-510.

Rampon C, Jiang CH, Dong H, Tang YP, Lockhart DJ, Schultz PG et al (2000). Effects of environmental enrichment on gene expression in the brain. Proc Natl Acad Sci USA 97: 12880-12884.

Rosenzweig MR, Bennett EL (1996). Psychobiology of plasticity: effects of training and experience on brain and behavior. J Neuropsychiatry Clin Neurosci 8: 459-470. 
Sanchis-Segura C, Spanagel R (2006). Behavioural assessment of drug reinforcement and addictive features in rodents: an overview. Addict Biol 11: 2-38.

Schnabel J (2009). Neuroscience: rethinking rehab. Nature 458: 25-27.

Setlow B (2008). Undoing cocaine's consequences on behavior and brain. Proc Natl Acad Sci USA 105: 16829-16830.

Shalev U, Grimm JW, Shaham Y (2002). Neurobiology of relapse to heroin and cocaine seeking: a review. Pharmacol Rev 54: 1-42.

Shepard JD, Bossert JM, Liu SY, Shaham Y (2004). The anxiogenic drug yohimbine reinstates methamphetamine seeking in a rat model of drug relapse. Biol Psychiatry 55: 1082-1089.

Sinha R (2001). How does stress increase risk of drug abuse and relapse? Psychopharmacology (Berl) 158: 343-359.

Solinas M, Chauvet C, Thiriet N, El Rawas R, Jaber M (2008). Reversal of cocaine addiction by environmental enrichment. Proc Natl Acad Sci USA 105: 17145-17150.

Solinas M, Thiriet N, El Rawas R, Lardeux V, Jaber M (2009). Environmental enrichment during early stages of life reduces the behavioral, neurochemical, and molecular effects of cocaine. Neuropsychopharmacology 34: 1102-1111.
Stairs DJ, Bardo MT (2009). Neurobehavioral effects of environmental enrichment and drug abuse vulnerability. Pharmacol Biochem Behav 92: 377-382.

Stalnaker TA, Takahashi Y, Roesch MR, Schoenbaum G (2009). Neural substrates of cognitive inflexibility after chronic cocaine exposure. Neuropharmacology 56(Suppl 1): 63-72.

Sweatt JD (2009). Experience-dependent epigenetic modifications in the central nervous system. Biol Psychiatry 65: 191-197.

Tanda G, Bassareo V, Di Chiara G (1996). Mianserin markedly and selectively increases extracellular dopamine in the prefrontal cortex as compared to the nucleus accumbens of the rat. Psychopharmacology (Berl) 123: 127-130.

van Praag H, Kempermann G, Gage FH (2000). Neural consequences of environmental enrichment. Nat Rev Neurosci 1: 191-198.

Verdejo-García A, Bechara A (2009). A somatic marker theory of addiction. Neuropharmacology 56(Suppl 1): 48-62.

Willner P (2005). Chronic mild stress (CMS) revisited: consistency and behavioural-neurobiological concordance in the effects of CMS. Neuropsychobiology 52: 90-110.

Supplementary Information accompanies the paper on the Neuropsychopharmacology website (http://www.nature.com/npp) 